\title{
Sutterella wadsworthensis gen. nov., sp. nov., Bile-Resistant Microaerophilic Campylobacter gracilis-Like Clinical Isolates
}

\author{
HANNAH M. WEXLER,,${ }^{1,2 *}$ DENISE REEVES, ${ }^{1}$ PAULA H. SUMMANEN,${ }^{2}$ ERIC MOLITORIS, ${ }^{2}$ \\ MAUREEN MCTEAGUE, ${ }^{3}$ JANE DUNCAN,${ }^{4}$ KENNETH H. WILSON,${ }^{4}$ \\ AND SYDNEY M. FINEGOLD ${ }^{2,3,5}$ \\ Research Service ${ }^{1}$ and Medical Service, ${ }^{3}$ Veterans Administration Medical Center, West Los Angeles, Wadsworth \\ Division, Los Angeles, California 90073; Department of Medicine ${ }^{2}$ and Department of Microbiology \\ and Immunology, ${ }^{5}$ UCLA School of Medicine, Los Angeles, California 90024; and Infectious \\ Diseases Section, Durham VA Medical Center, Durham, North Carolina $27705^{4}$
}

\begin{abstract}
Campylobacter gracilis (formerly Bacteroides gracilis) is an asaccharolytic, nitrate-positive, urease-negative organism that requires formate and fumarate or hydrogen as a growth additive and may pit agar media. Clinical isolates that were obtained primarily from appendiceal and peritoneal fluid specimens and initially were identified in our laboratory as $B$. gracilis were later found to include "unusual" strains that could be distinguished by biochemical and genetic criteria. These unusual $C$. gracilis strains were bile resistant, could not reduce tetrazolium chloride under aerobic conditions if formate and fumarate were added to the medium, and could grow in the presence of 2 or $6 \%$ oxygen if no blood was added to the medium. $C$. gracilis, other campylobacters, and the unusual strains produced distinctive dehydrogenase patterns when gels were incubated anaerobically. A cellular fatty acid analysis revealed that the cluster formed by the unusual organisms was distinct from the (separate) clusters formed by $C$. gracilis, Bacteroides ureolyticus, and other Campylobacter species. 16S rRNA sequence data indicated that these organisms are not related phylogenetically to either $C$. gracilis or other Campylobacter species; the most closely related taxa as determined by rRNA sequence analysis were unrelated aerobes (members of the genera Bordetella, Alcaligenes, Rhodocyclus, and Comamonas). DNA homology data confirmed that these taxa are separate groups. Our data indicate that the unusual organisms are members of a new genus and new species, for which we propose the name Sutterella wadsworthensis. The type strain of $S$. wadsworthensis is strain WAL 9799 (= ATCC 51579).
\end{abstract}

The bacteria originally known as Bacteroides ureolyticus and later as the $B$. ureolyticus group are asaccharolytic, nitratepositive organisms that require formate or hydrogen as an electron donor and may pit agar media. B. ureolyticus and Bacteroides gracilis clearly do not belong to the genus Bacteroides sensu stricto (currently limited to the Bacteroides fragilis group [13]), and the results of 16S rRNA sequence analysis and DNA-rRNA hybridization studies support the hypothesis that there is a tight homology group that includes $B$. ureolyticus, $B$. gracilis, and the genus Campylobacter (including some species previously placed in the genus Wolinella $)(10,17)$. It has been proposed that both $B$. ureolyticus and $B$. gracilis are microaerophiles and not anaerobes (and therefore should be included in the group containing the true campylobacters) (5). B. gracilis has been reclassified as Campylobacter gracilis, and this name is used below. However, while B. ureolyticus is considered a member of the family Campylobacteraceae, it was not renamed along with $C$. gracilis; the recommended status of this taxon was a species incertae sedis pending further investigation (16).

C. gracilis was obtained originally from a gingival crevice (15). We have examined the role of $C$. gracilis in various nondental infections and have found that it is more likely to be involved in serious deep-seated infections than $B$. ureolyticus is (6). During biochemical characterization and susceptibility testing of isolates obtained from clinical specimens in the Wads-

\footnotetext{
* Corresponding author. Mailing address: Microbial Diseases Research Laboratory, Bldg. 304, Room E3-224, VAMC West Los Angeles 691/151J, Los Angeles, CA 90073. Phone: (310) 268-3404. Fax: (310) 268-4646.
}

worth Anaerobe Laboratory, we observed heterogeneity among the strains previously identified as $C$. gracilis. These organisms differed in their bile resistance and their ability to reduce triphenyltetrazolium chloride (TTC). Isolates that were bile resistant and unable to reduce TTC aerobically were compared with other strains of $C$. gracilis (including the American Type Culture Collection type strain) and strains of five other Campylobacter species by using biochemical characteristics, cellular fatty acid profiles, levels of DNA homology, and levels of $16 \mathrm{~S}$ rRNA sequence homology.

In this paper, we describe the results of these taxonomic and phylogenetic studies. We concluded that these organisms are members of a new genus and new species, for which we propose the name Sutterella wadsworthensis. The type strain of $S$. wadsworthensis is strain WAL 9799 (= ATCC 51579).

\section{MATERIALS AND METHODS}

Bacterial strains. The strains used in this study included 37 human clinical isolates obtained from the Wadsworth Anaerobic Bacteriology Laboratory collection and one strain each of Campylobacter sp. and C. gracilis type 2 kindly provided by Anne Tanner (Forsyth Dental Center, Boston, Mass.) (Table 1). The American Type Culture Collection strains used as controls included B. gracilis ATCC $33236^{\mathrm{T}}$ (T = type strain), Campylobacter showae ATCC $51146^{\mathrm{T}}$, Campylobacter concisus ATCC $33237^{\mathrm{T}}$, Campylobacter rectus ATCC $33238^{\mathrm{T}}$, Campylobacter curvus ATCC $35224^{\mathrm{T}}$, and Campylobacter sputorum ATCC $35980^{\mathrm{T}}$.

Oxygen tolerance. Strains were grown for 48 to $72 \mathrm{~h}$ in an anaerobic chamber on brucella agar supplemented with $0.3 \%$ formate and $0.3 \%$ fumarate with and without $5 \%$ laked sheep blood. Aerolerance was determined by transferring the strains to agar plates containing the medium described above and incubating the plates in an atmosphere containing either 2 or $6 \% \mathrm{O}_{2}$. The oxygen concentration desired was obtained by using an automated evacuation-replacement technique (Anoxomat; Mart BV Laboratorium, Lichtenvoorde, Holland). 
TABLE 1. Isolates used and their sources and GenBank accession numbers

\begin{tabular}{|c|c|c|c|}
\hline Strain $^{a}$ & Other designation ${ }^{a}$ & $\begin{array}{l}\text { GenBank nucleotide sequence } \\
\text { accession no. }\end{array}$ & Source \\
\hline \multicolumn{4}{|l|}{ C. gracilis (previously B. gracilis) strains } \\
\hline WAL 6823 & & & Pleural fluid \\
\hline WAL 7701 & & & Brain abscess \\
\hline WAL 7728 & & & Brain abscess \\
\hline WAL 8030 & & & Maxilla \\
\hline WAL 8072 & & & Neck mass \\
\hline WAL 9656 & & & Appendix \\
\hline WAL 10160 & & & Periodontal \\
\hline WAL 10204 & & & Pleural fluid \\
\hline WAL 6989 & ATCC $33236^{\mathrm{T}}$ & L.37787 & Gingival sulcus \\
\hline C. gracilis type 2 strain WAL 10733 & FDC $20 \mathrm{~A} 1^{b}$ & & Periodontal (oral pocket) \\
\hline \multicolumn{4}{|l|}{ S. wadsworthensis strains } \\
\hline WAL 7095 & & & Appendiceal abscess \\
\hline WAL 7115 & & & Peritoneal fluid \\
\hline WAL 7877 & & L37785 & Appendix \\
\hline WAL 8074 & & & Unknown \\
\hline WAL 8522 & & & Peritoneal fluid \\
\hline WAL 8870 & & & Abdominal fluid \\
\hline WAL 8948 & & & Appendix \\
\hline WAL 8960 & & & Peritoneal fluid \\
\hline WAL 8962 & & & Appendix \\
\hline WAL 9041 & & & Appendix \\
\hline WAL 9054 & & L37786 & \\
\hline WAL 9156 & & & Peritoneal fluid \\
\hline WAL 9244 & & & Appendix \\
\hline WAL 9317 & & & Abdominal fluid \\
\hline WAL 9631 & & & Appendix \\
\hline WAL 9689 & & & Appendix \\
\hline WAL $9799^{\mathrm{T}}$ & ATCC $51579^{\mathrm{T}}$ & & Abdominal fluid \\
\hline WAL 11060 & & & Appendix \\
\hline WAL 11078 & & & Peritoneal fluid \\
\hline WAL 11175 & & & Peritoneal fluid \\
\hline \multicolumn{4}{|l|}{ C. concisus strains } \\
\hline WAL $9036^{\mathrm{T}}$ & ATCC $33237^{\mathrm{T}}$ & & Gingival sulcus \\
\hline WAL 10200 & & & Transtracheal aspirate \\
\hline WAL 10277 & & & Lung aspirate \\
\hline \multicolumn{4}{|l|}{ C. curvus strains } \\
\hline ATCC $35224^{\mathrm{T}}$ & & & Jaw abscess \\
\hline WAL 8827 & & & Peritoneal fluid \\
\hline WAL 9636 & & & \\
\hline \multicolumn{4}{|l|}{ C. rectus strains } \\
\hline ATCC $33238^{\mathrm{T}}$ & & & Periodontal \\
\hline WAL 7791 & & & Peritoneal fluid \\
\hline WAL 7943 & & & Appendix \\
\hline WAL 9675 & & & Appendix \\
\hline WAL 10143 & & & Neck abscess \\
\hline C. showae WAL $10729^{\mathrm{T}}$ & ATCC $51146^{\mathrm{T}}$ & & Gingival crevice \\
\hline C. sputorum WAL $10734^{\mathrm{T}}$ & ATCC $35980^{\mathrm{T}}$ & & Oral cavity \\
\hline \multicolumn{4}{|l|}{ Campylobacter sp. strains } \\
\hline WAL 4864 & & & Transtracheal aspirate \\
\hline WAL 10732 & FDC $286^{b}$ & & Periodontal (oral pocket) \\
\hline
\end{tabular}

${ }^{a}$ WAL, Wadsworth Anaerobe Laboratory; ATCC, American Type Culture Collection; FDC, Forsyth Dental Center.

"Strain obtained from Anne Tanner.

Effect of bile. The effect of bile was determined by using $20 \%$ bile disks (Remel, Lenexa, Kans.) as described previously (14).

Enzyme activities. Enzyme activities were determined by using an API ZYM kit (Analytab Products, Plainview, N.Y.). Urease activity was determined with urease disks according to the directions of the manufacturer (Rosco Diagnostics, Taastrup, Denmark). Indoxyl acetate hydrolysis was determined as described previously (11). Oxidase activity was also determined as described previously (14).

Reduction of TTC. The ability to reduce TTC was determined by inoculating brucella base laked blood agar (with and without formate and fumarate) with $10^{5}$ CFU by using a Steers replicator, incubating the plate for 48 to $72 \mathrm{~h}$ anaerobically, and dropping a solution containing equal parts $0.1 \%$ TTC and $2 \%$ molten agar onto the inoculum spots. These tests were performed either in an anaerobic chamber or in the ambient atmosphere within $5 \mathrm{~min}$ of the time that the plates were removed from the anaerobic chamber. Reduction of TTC was determined by the appearance of a red color, which indicated that formazan had been formed.

Dehydrogenase analysis. Cells were grown for 48 to $72 \mathrm{~h}$ on brucella blood agar plates supplemented with $0.3 \%$ formate and $0.3 \%$ fumarate in an anaerobic chamber and were then suspended in $0.1 \mathrm{M}$ HEPES $(N$-2-hydroxyethylpiperazine- $N^{\prime}$-2-ethanesulfonic acid) buffer ( $\mathrm{pH} 7.5$ ). The cells were disrupted by three passes through a French pressure cell (SLM Instruments, Inc., Urbana, III.), and a cell-free supernatant was obtained by centrifuging each preparation at 37,000 $\times g$ for $15 \mathrm{~min}$. Undenatured samples containing $20 \mu \mathrm{g}$ of protein were subjected to polyacrylamide gel electrophoresis on a $4 \%$ stacking gel and a $10 \%$ running gel at $25 \mathrm{~mA}$ and $200 \mathrm{~V}(7)$. The gels were stained overnight in a solution containing $0.08 \mathrm{M}$ Tris $(\mathrm{pH} 7.5)$, malate $(2 \mathrm{mg} / \mathrm{ml})$, phenazine methosulfate $(0.04$ $\mathrm{mg} / \mathrm{ml})$, thiazolyl blue tetrazolium $(0.2 \mathrm{mg} / \mathrm{ml})$, and NAD $(0.1 \mathrm{mg} / \mathrm{ml})$. For 
staining, the gels were incubated anaerobically with and without substrate (to distinguish substrate-specific bands from nonspecific bands) and under ambient conditions.

Cellular fatty acid analysis. Organisms were initially identified by using the Microbial Identification System, which analyzes cell wall fatty acids. The fatty acid methyl esters of whole-cell extracts were identified by the method of Moss and Nunez-Montiel (9). Briefly, cells were grown for 48 to $72 \mathrm{~h}$ in peptone-yeast extract-glucose medium (Carr Scarborough, Stone Mountain, Ga.) supplemented with formate and fumarate. Growth was harvested by centrifugation at $5,000 \times g$ for $20 \mathrm{~min}$, and the resulting pellets were kept frozen at $-20^{\circ} \mathrm{C}$ until they were processed. The cells were saponified in aqueous methanol, methylated in hydrochloric acid in aqueous methanol, extracted in hexane and methyl-tertbutyl ether, washed in dilute $\mathrm{NaOH}$, and analyzed with a model $5890 \mathrm{~A}$ gas-liquid chromatograph (Hewlett-Packard) equipped with a silicone-lined capillary column by using the Microbial ID software package (MIDI; Microbial ID, Inc. Newark, Del.).

16S rRNA sequencing. Nucleic acids were purified as described previously. RNA was purified, and the sequence of the 16S rRNA fragment was determined by using reverse transcriptase as described previously (18). DNA was amplified by using primers directed at sequences specific for eubacterial $16 \mathrm{~S}$ ribosoma DNA (4). The PCR product was reamplified by using the method of Zintz and Beebe (19). The resulting amplicons were sequenced by using a DyeDeoxy terminator sequencing kit (Applied Biosystems, Foster City, Calif.) in conjunction with a model 373A automated sequencer (Applied Biosystems). A phylogenetic analysis was performed by using the maximum-likelihood method (3) and the entire 16S rRNA sequence. The GenBank and Ribosomal Database Project databases were searched for similar sequences in PCGENE (Intelligenetics, Mountain View, Calif.) by using the program FSTNSCAN (a subroutine of PCGENE), and the 20 most similar sequences were identified. The phylogenetic tree available from the Ribosomal Database Project indicated that these sequences could be located in two (separate) clusters, and representative sequences from these two regions of the tree were included in our tree.

DNA extraction and purification. Strains were grown as described above. The growth from three or four plates was scraped into tubes containing $0.5 \mathrm{ml}$ of Tris-EDTA (10 mM Tris [pH 7.6], $1 \mathrm{mM}$ EDTA), centrifuged for 15 to $20 \mathrm{~min}$ at $8,000 \mathrm{rpm}(8,000 \times g)$, and resuspended in Tris-EDTA. The suspensions were treated with lysozyme $(1 \mathrm{mg} / \mathrm{ml})$ for $30 \mathrm{~min}$ at $37^{\circ} \mathrm{C}$. Sodium dodecyl sulfate (final concentration, $0.5 \%$ ) and proteinase $\mathrm{K}$ (final concentration, $0.1 \mathrm{mg} / \mathrm{ml}$ ) were then added, and the suspensions were incubated for $60 \mathrm{~min}$ at $37^{\circ} \mathrm{C}$. Hexadecyltrimethylammonium bromide (final concentration, $1 \%$ ) was added (to solubilize the lipopolysaccharide), and the suspensions were incubated at $65^{\circ} \mathrm{C}$ for $20 \mathrm{~min}$. Then the DNA was extracted by using an equal volume of chloroform-isoamyl alcohol (24:1). The aqueous phase was removed and extracted by using an equal volume of phenol-chloroform-isoamyl alcohol (25:24:1). The DNA was then precipitated from the aqueous supernatant with $\mathrm{NaCl}$ (final concentration, $1 \mathrm{M}$ ) and 0.6 volume of isopropanol. The DNA pellets were then redissolved in $300 \mu \mathrm{l}$ of Tris-EDTA and treated with $4 \mu \mathrm{l}$ of RNase $(10 \mathrm{mg} / \mathrm{ml})$ for $60 \mathrm{~min}$ at $50^{\circ} \mathrm{C}$. The final extraction was performed by using an equal volume of chloroform-isoamyl alcohol. The preparations were then precipitated with sodium acetate (final concentration, $0.3 \mathrm{M}$ ) and 2 volumes of $95 \%$ ethanol, washed twice with $70 \%$ ethanol, and resuspended in $200 \mu \mathrm{l}$ of $0.42 \mathrm{M} \mathrm{NaCl}$. DNA concentration and purity were determined spectrophotometrically.

Preparation of labeled DNA. DNA was sheared by sonication with a Microson XL 2500 apparatus (Heat Systems, Farmington, N.Y.) for $4 \mathrm{~min}$ at a power setting of 4 by using a microcup horn to give a fragment size of approximately 500 bp. Each reference DNA was labeled with $\left[1^{\prime}, 2^{\prime}, 5^{\prime}-{ }^{3} \mathrm{H}\right] \mathrm{dCTP}$ by nick translation by using a commercial nick translation kit (Amersham Corp., Arlington Heights, III.) according to manufacturer's instructions. The labeled DNA was separated from unincorporated nucleotides by gel exclusion chromatography by using Sephadex G-50.

DNA-DNA hybridization. Unlabeled DNA preparations were sheared as described above. DNA-DNA reassociation experiments and $\mathrm{S} 1$ nuclease treatments were performed as described previously (12). Briefly, $0.02 \mu \mathrm{g}$ of labeled reference DNA and $20 \mu \mathrm{g}$ of unlabeled DNA in $200 \mu \mathrm{l}$ of $0.42 \mathrm{M} \mathrm{NaCl}$ were denatured at $100^{\circ} \mathrm{C}$ and hybridized at 65 or $70^{\circ} \mathrm{C}$ (as indicated in Table 2) for 90 $h$ in screw-cap microcentrifuge tubes. Fifty-four microliters of S1 nuclease (Sigma Chemical Co., St. Louis, Mo.) was added to a final concentration of $95 \mathrm{U} / \mathrm{ml}$, and the tubes were then incubated for $20 \mathrm{~min}$ at $50^{\circ} \mathrm{C}$. Precipitates were collected on nitrocellulose filters (pore size, $0.45 \mu \mathrm{m}$; type HAWP; Millipore Corp., Bedford, Mass.), dried, and counted with a model LS 6000 TA liquid scintillation counter (Beckman Instruments, Fullerton, Calif.). All hybridization experiments were performed in triplicate. Levels of hybridization were corrected for selfreassociation by using calf thymus DNA as a control. Levels of homology were determined by comparison with the corrected absolute value obtained for hybridized homologous DNA.

Antimicrobial agent susceptibility tests. The MICs of antimicrobial agents for selected strains were determined as described previously (14) with formate and fumarate added to the media.

Nucleotide sequence accession numbers. The 16S rRNA sequences of $S$. wadsworthensis WAL 7877 and WAL 9054 and B. gracilis (C. gracilis) WAL $6989^{\mathrm{T}}$ $\left(=\right.$ ATCC $33236^{\mathrm{T}}$ ) have been deposited in the GenBank database under accession numbers L37785, L37786, and L37787, respectively.
TABLE 2. Levels of DNA-DNA homology for 20 Sutterella strains, 10 C. gracilis strains, and 11 strains belonging to other Campylobacter species

\begin{tabular}{|c|c|c|c|}
\hline \multirow{2}{*}{$\begin{array}{c}\text { Source of } \\
\text { unlabeled DNA }\end{array}$} & \multicolumn{3}{|c|}{ \% Homology with labeled DNA from: } \\
\hline & $\begin{array}{l}\text { S. wadsworthensis } \\
\text { WAL } 9799^{\mathrm{T} a}\end{array}$ & $\begin{array}{c}\text { C. gracilis } \\
\text { ATCC } 33236^{\mathrm{T} b}\end{array}$ & $\begin{array}{l}\text { C. gracilis } \\
\text { WAL } 8030^{b}\end{array}$ \\
\hline \multicolumn{4}{|l|}{ Sutterella strains } \\
\hline WAL 9799 & 100 & 0 & 0 \\
\hline WAL 7095 & 97 & 3 & \\
\hline WAL 7115 & 81 & & \\
\hline WAL 7877 & 67 & 0 & \\
\hline WAL 8074 & 100 & & \\
\hline WAL 8522 & 71 & 0 & \\
\hline WAL 8870 & 78 & & \\
\hline WAL 8948 & 100 & 0 & \\
\hline WAL 8960 & 102 & 0 & \\
\hline WAL 8962 & 100 & & \\
\hline WAL 9041 & 96 & 5 & \\
\hline WAL 9156 & 100 & 0 & \\
\hline WAL 9244 & 100 & & \\
\hline WAL 9317 & 100 & & \\
\hline WAL 9631 & 98 & 12 & \\
\hline WAL 9689 & 85 & 0 & \\
\hline WAL $9899^{\mathrm{T}}$ & 104 & 0 & \\
\hline WAL 11060 & 100 & & \\
\hline WAL 11078 & 100 & 0 & 0 \\
\hline WAL 11175 & 83 & 0 & \\
\hline \multicolumn{4}{|l|}{ C. gracilis strains } \\
\hline ATCC $33236^{\mathrm{T}}$ & 0 & 100 & \\
\hline WAL 8030 & 0 & 43 & 100 \\
\hline WAL 6823 & 0 & 22 & \\
\hline WAL 7701 & 0 & 30 & 48 \\
\hline WAL 7728 & 2 & 30 & \\
\hline WAL 8072 & 0 & 42 & 74 \\
\hline WAL 9656 & 0 & 33 & 58 \\
\hline WAL 10160 & 0 & 75 & 43 \\
\hline WAL 10204 & 0 & 79 & \\
\hline WAL $10733^{c}$ & & 42 & 58 \\
\hline $\begin{array}{l}\text { Campylobacter sp. strain } \\
\text { WAL } 4864\end{array}$ & 0 & & \\
\hline C. rectus WAL 7791 & 0 & & \\
\hline C. rectus WAL 7943 & & 15 & \\
\hline C. curvus WAL 9636 & 0 & 0 & \\
\hline C. rectus WAL 9675 & 0 & 1 & \\
\hline C. rectus WAL 10143 & 0 & 0 & \\
\hline $\begin{array}{l}\text { Campylobacter sp. strain } \\
\text { WAL } 10732^{d}\end{array}$ & 0 & & \\
\hline C. concisus ATCC $33237^{\mathrm{T}}$ & 0 & 0 & \\
\hline C. rectus ATCC $33238^{\mathrm{T}}$ & 2 & 15 & 23 \\
\hline C. curvus ATCC $35224^{\mathrm{T}}$ & 0 & 0 & \\
\hline C. sputorum ATCC $35980^{\mathrm{T}}$ & & 0 & \\
\hline C. showae ATCC $51146^{\mathrm{T}}$ & 1 & 0 & \\
\hline
\end{tabular}

${ }^{a}$ Levels of hybridization at $70^{\circ} \mathrm{C}$

${ }^{b}$ Levels of hybridization at $65^{\circ} \mathrm{C}$.

c $C$. gracilis type 2 strain obtained from Anne Tanner

"Campylobacter sp. strain most closely related to $C$. showae and obtained from Anne Tanner.

\section{RESULTS}

Resistance to bile. Strains belonging to the typical $C$. gracilis group were sensitive to bile, while the Sutterella strains were bile resistant. The strains that grouped with Campylobacter species were variable in their resistance to bile.

Reduction of TTC. TTC reduction by $C$. gracilis was affected by the basal growth medium and atmosphere used. Both the typical $C$. gracilis strains and Sutterella strains reduced TTC in an anaerobic atmosphere on blood agar plates when no formate and fumarate were added, but did not reduce TTC aer- 


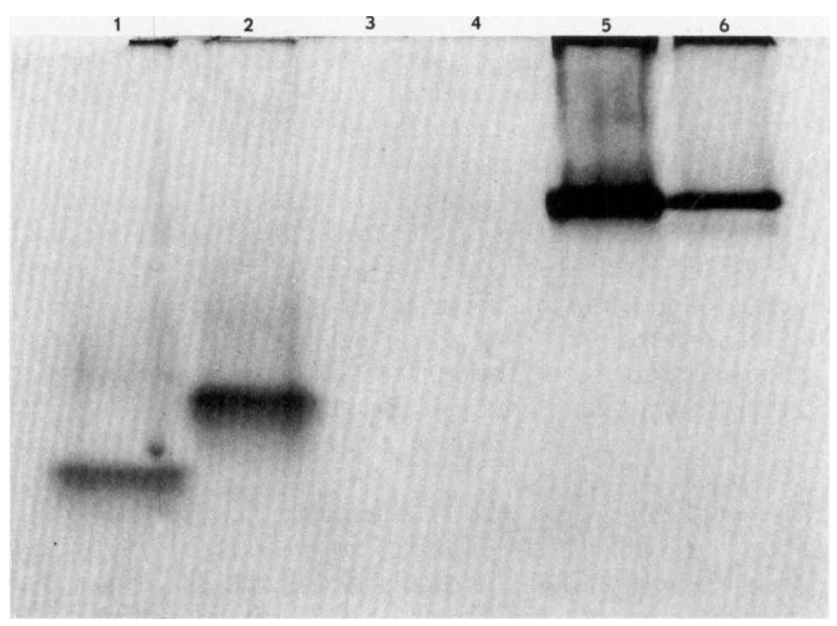

FIG. 1. Malate dehydrogenase patterns of C. gracilis, Sutterella, and Campylobacter strains. Gels were incubated anaerobically. Lane $1, C$. rectus ATCC $33238^{\mathrm{T}}$; lane 2, C. showae WAL $10729^{\mathrm{T}}$; lane 3, C. gracilis ATCC $33236^{\mathrm{T}}$; lane 4 C. gracilis WAL 8030; lane 5, S. wadsworthensis WAL $9799^{\mathrm{T}}\left(=\right.$ ATCC $51579^{\mathrm{T}}$ ); lane $6, S$. wadsworthensis WAL 8960 . Lanes 5 and 6 contained non-substratespecific dehydrogenase activity with anaerobic incubation if the gel was incubated anaerobically. Substrate-specific Campylobacter bands were present under both aerobic and anaerobic incubation conditions.

obically. However, if formate and fumarate were added to the medium, the typical $C$. gracilis strains reduced TTC in an aerobic atmosphere (as did Campylobacter and $B$. ureolyticus strains), while Sutterella strains did not.

Dehydrogenase profiles. Three general patterns of dehydrogenase activity were observed with the typical $C$. gracilis, $S$. wadsworthensis, and Campylobacter strains which we studied (Fig. 1). The members of the group that included the type strain of $C$. gracilis (as well as $C$. gracilis type 2 strain WAL 10733 [FDC 20A1]) produced no bands or very faintly reactive malate-specific bands (which appeared only when the gels were very heavily loaded), whereas the members of the Sutterella group produced strongly reactive single or multiple nonspecific dehydrogenase bands (but only when they were incubated anaerobically). The Campylobacter strains (including strain WAL 10732 [FDC 286]) produced different malate dehydrogenase-specific bands that migrated various distances under both aerobic and anaerobic incubation conditions. As the different Campylobacter species cannot be differentiated by using routine biochemical tests, malate dehydrogenase profiles may provide a useful tool for identifying species belonging to this genus.

Cellular fatty acid analysis. The fatty acid methyl esters found in the different groups of organisms are shown in Table 3. A cluster analysis of the cellular fatty acid data revealed the following three major groups: (i) typical $C$. gracilis (including

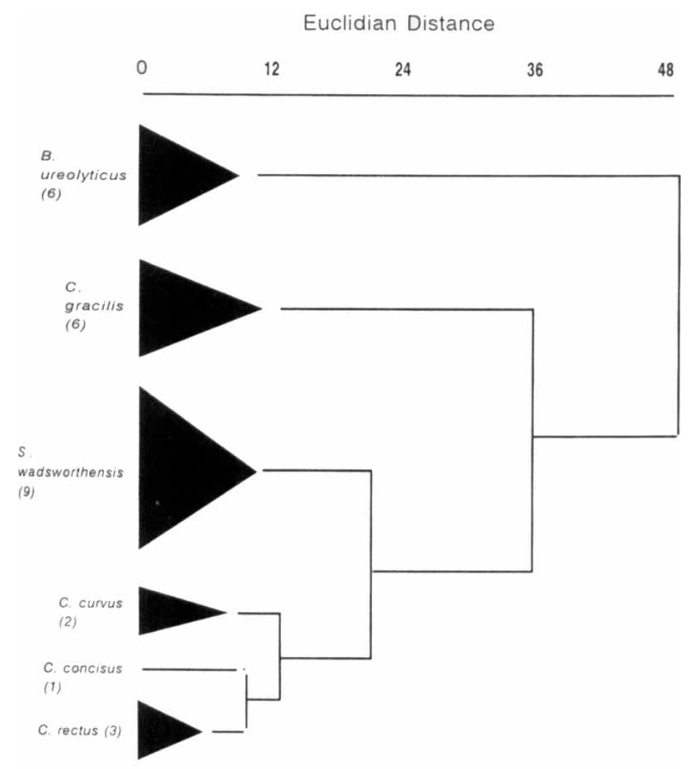

FIG. 2. Dendrogram based on the results of a cellular fatty acid cluster analysis showing the positions of $C$. gracilis, other Campylobacter species, and $S$. wadsworthensis. Numbers in parentheses are the numbers of strains.

strain ATCC $33236^{\mathrm{T}}$ ), (ii) the Sutterella group, and (iii) Campylobacter species (Fig. 2). Among other things, the absence of the 12:0 fatty acid methyl ester distinguished Sutterella strains from typical $C$. gracilis strains and strains of other Campylobacter species. The typical $C$. gracilis strains, Campylobacter strains, and $B$. ureolyticus strains also clustered quite independently of each other. $S$. wadsworthensis WAL 9799 was selected as the type strain because it occurred in the center of the Sutterella cluster. C. gracilis ATCC $33236^{\mathrm{T}}$ occurred at the edge of the $C$. gracilis cellular fatty acid cluster.

Biochemical characteristics and oxygen tolerance. Like $B$. ureolyticus, C. gracilis, and other Campylobacter species, members of the genus Sutterella were asaccharolytic and reduced nitrate to nitrite. Both Campylobacter and Sutterella strains grew on solid media in the presence of 2 and $6 \%$ oxygen. $C$. gracilis grew in the presence of $6 \%$ oxygen only on plates containing brucella agar supplemented with formate and fumarate with no blood added; if blood was added, $C$. gracilis did not grow.

16S rRNA sequencing. We determined the 16S rRNA sequences of $C$. gracilis ATCC $33236^{\mathrm{T}}$, C. rectus WAL 7943, and two Sutterella strains (WAL 9054 and WAL 7877). C. rectus WAL 7943 was most similar to C. rectus ATCC $33238^{\mathrm{T}}$; these two strains differed at only 2 of 1,420 base pairs (level of similarity, $99.9 \%)$. The type strain of $C$. gracilis was also very

TABLE 3. Cell wall fatty acid analysis of $C$. gracilis strains, Sutterella strains, and strains of other Campylobacter species

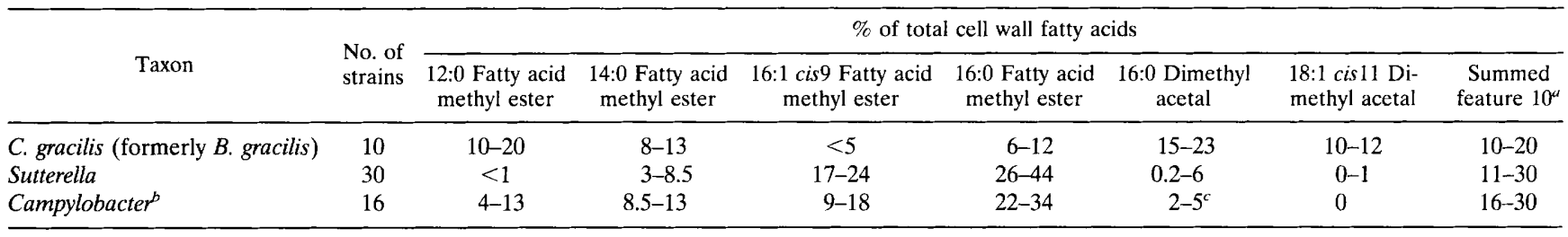

${ }^{a} 18: 1 \mathrm{C} 11 / \mathrm{t} 9 / \mathrm{t} 6$ fatty acid methyl ester and/or unknown peak at 17.834 .

${ }^{b}$ The strains examined included eight $C$. rectus strains, three $C$. curvus strains, three $C$. concisus strains, and two Campylobacter sp. strains.

${ }^{c}$ The $C$. curvus strains contained 2 to 5\% 16:0 dimethyl acetal, and the other Campylobacter strains contained none of this compound. 


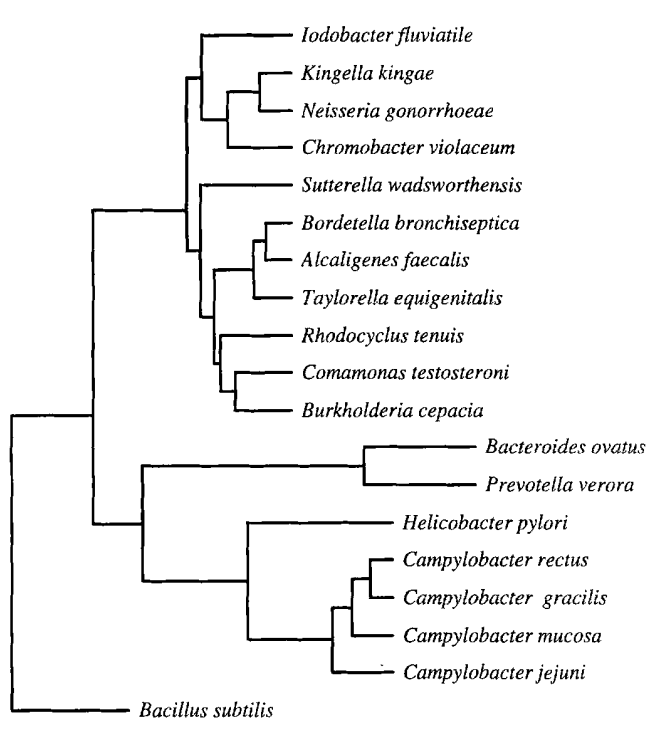

0.10

FIG. 3. Phylogenetic tree showing the positions of $S$. wadsworthensis, C. gracilis, other Campylobacter species, and related organisms based on 16S rRNA sequence similarity data.

similar to $C$. rectus, but the level of sequence similarity was lower $(96 \%)(1,432$ base pairs were compared). A phylogenetic tree constructed by using the maximum-likelihood method is shown in Fig. 3. C. gracilis ATCC $33236^{\mathrm{T}}$ branches at the same point as $C$. rectus and belongs to a cluster that contains other Campylobacter species. The 16S rRNA sequences of the two Sutterella strains (WAL 9054 and WAL 7877 [1,454 and 1,419 base pairs were sequenced, respectively]) were identical to each other but were not similar to the sequences of the $C$. gracilis and Campylobacter strains analyzed or the sequences obtained from the GenBank, Ribosomal Database Project, and PCgene databases. A total of 15 sequences (the sequences of 13 named and 2 unnamed Campylobacter species) were included in the comparison. The taxa that were most closely related to the two Sutterella strains as determined by $16 \mathrm{~S}$ rRNA sequences were unrelated aerobes (members of the genera Bordetella, Alcaligenes, Rhodocyclus, and Comamonas), as shown by the phylogenetic tree in Fig. 3.

DNA hybridization. The levels of DNA-DNA homology between members of the groups examined are shown in Table 2. ${ }^{3} \mathrm{H}$-labeled DNA from C. gracilis ATCC $33236^{\mathrm{T}}$ hybridized moderately with the DNAs of other typical $C$. gracilis strains (the levels of homology were 70 to $80 \%$ for two of nine strains, 40 to $50 \%$ for three of nine strains, 30 to $50 \%$ for three of nine strains, and $22 \%$ for one of nine strains). The DNAs of 10 Sutterella strains did not hybridize at all with the DNA of the $C$. gracilis type strain, and the DNAs of three Sutterella strains hybridized very slightly (levels of homology, 3.5 and $12 \%$ ). The DNAs of seven Campylobacter strains did not hybridize at all with C. gracilis ATCC $33236^{\mathrm{T}}$ DNA, and the DNAs of two strains of $C$. rectus hybridized slightly (level of homology, $15 \%$ ). ${ }^{3} \mathrm{H}$-labeled DNA from another $C$. gracilis strain (WAL 8030 ) hybridized more strongly with the DNAs of other $C$. gracilis strains, did not hybridize at all with the DNAs of Sutterella strains, and hybridized slightly with the DNA of the single $C$. rectus strain tested (level of homology, 23\%).

${ }^{3} \mathrm{H}$-labeled DNA from strain WAL 9799 (the $S$. wadsworthensis type strain) did not hybridize with the DNAs of $10 C$. gracilis strains or the DNAs of nine strains belonging to other
Campylobacter species, but hybridized strongly (levels of homology, $\geq 96 \%$ ) with the DNAs of $68 \%$ of the Sutterella strains (19 strains) and exhibited levels of homology of $\geq 67 \%$ with all of the Sutterella strains tested, indicating that these strains belong to the same species (1).

Clinical sources. The strains belonging to the Sutterella group were isolated mainly from infections of gastrointestinal tracts (Table 1). C. gracilis strains were found virtually only in infections that occurred above the diaphragm (brain, pleural fluid, etc.); only one strain of $C$. gracilis was isolated from an appendiceal specimen. The resistance of the Sutterella strains to both human bile (unpublished data) and oxgall is notable; this may account for the ability of these organisms to survive in biliary tracts and bowels.

Metronidazole resistance of $\boldsymbol{C}$. gracilis. The typically poor growth of $C$. gracilis strains (even on control plates) makes endpoint determinations particularly difficult. We found that adding the growth supplements formate and fumarate made determining MICs easier and minimized the "haze" observed even at high antimicrobial agent concentrations. The MICs for C. gracilis were considerably lower when formate and fumarate were added to the medium. We used TTC to facilitate endpoint determinations and established a new antibiogram for this organism (8). We subsequently reanalyzed the susceptibility profiles of these organisms in light of our revised classification and found that the metronidazole-resistant strains all belonged to the oxygen-tolerant, bile-resistant Sutterella group. Antibiograms for the new taxa belonging to this group should be determined.

\section{DISCUSSION}

Strains of $C$. gracilis (formerly B. gracilis) are associated with severe infections and high levels of resistance to several antimicrobial agents, although recently we have found that incorporating formate and fumarate into media (which results in better growth of these organisms) results in clearer and considerably lower MICs. Previous studies performed in our laboratory revealed that $C$. gracilis was more likely than $B$. ureolyticus to cause serious and deep-seated infections (6). In this study, we found that all of the $C$. gracilis strains except one were isolated from infections that occurred above the diaphragm, while most of the Sutterella strains were isolated from infections that occurred below the diaphragm, and that the metronidazole-resistant strains all belonged to the genus Sutterella. The relative importance of these two taxa in infections of various types and the differences in their antibiograms should be evaluated in light of the revised taxonomic status of these organisms. Workers in a clinical laboratory can easily distinguish Sutterella strains, C. gracilis strains, and strains of other Campylobacter species by using two criteria, resistance to $20 \%$ bile disks and cell wall fatty acid patterns. One of the differences is the absence of 12:0 fatty acid methyl ester in Sutterella strains. The fatty acid patterns of $C$. gracilis strains and other Campylobacters include 12:0 fatty acid methyl ester, as described previously (2).

The results of previous $16 \mathrm{~S}$ rRNA sequence studies have suggested that $C$. gracilis belongs phylogenetically to the group that contains the true campylobacters (10). Our results for the 16S rRNA sequence of $C$. gracilis were virtually identical to the previously published sequence (the same strain was used) (2); these sequences differed at only 1 of 1,381 bases after resolution of some ambiguous positions. A phylogenetic analysis revealed that the strains of $C$. gracilis tested were very closely related to Campylobacter species. Vandamme et al. (16) found that $C$. gracilis differed from some campylobacters only in the 
TABLE 4. Characteristics of B. ureolyticus, the genus Campylobacter, C. gracilis, and the genus Sutterella

\begin{tabular}{|c|c|c|c|c|c|c|c|}
\hline \multirow{2}{*}{ Taxon } & \multirow{2}{*}{$\begin{array}{l}\text { Oxidase } \\
\text { activity }\end{array}$} & \multirow{2}{*}{$\begin{array}{l}\text { Urease } \\
\text { activity }\end{array}$} & \multirow{2}{*}{$\begin{array}{l}\text { Indoxyl } \\
\text { acetate }\end{array}$} & \multicolumn{2}{|c|}{$\begin{array}{l}\text { Growth in the } \\
\text { presence of: }\end{array}$} & \multirow{2}{*}{$\begin{array}{l}\text { Resistance to } \\
20 \% \text { bile }\end{array}$} & \multirow{2}{*}{$\begin{array}{l}\text { TTC } \\
\text { reduction }\end{array}$} \\
\hline & & & & $2 \% \mathrm{O}_{2}$ & $6 \% \mathrm{O}_{2}$ & & \\
\hline B. ureolyticus & $t^{b}$ & + & NT & + & + or $w$ & $\mathrm{~S}$ & NT \\
\hline Campylobacter & + & - & $\mathrm{V}$ & + & + & $\mathrm{V}^{\mathrm{c}}$ & + \\
\hline C. gracilis (formerly B. gracilis) & - & - & t & + & $-{ }^{d}$ & $\mathrm{~S}$ & + \\
\hline Sutterella & - & - & - & + & $+(-)$ & $\mathrm{R}$ & - \\
\hline
\end{tabular}

a Ability to reduce TTC in an aerobic atmosphere when formate and fumarate are added to the medium.

$b^{b}+$, positive; - , negative; NT, not tested; V, variable within the same species; w, weakly positive; S, sensitive; R, resistant; $+(-)$, occasional strains negative.

c The strains tested included two $C$. curves strains (which were resistant), four $C$. rectus strains (which were sensitive), one $C$. concisus strain (which was sensitive), and Campylobacter sp. strain WAL 4864 (which exhibited an intermediate level of sensitivity).

${ }^{d}$ In the presence of $6 \% \mathrm{O}_{2} C$. gracilis grew only on plates containing brucella agar supplemented with formate and fumarate but no blood; if blood was added, $C$. gracilis did not grow.

absence of flagella and the absence of oxidase activity; these authors commented that the cytochrome pattern of $C$. gracilis resembles the pattern reported for the genus Campylobacter and that the lack of measurable oxidase activity is not the result of a fundamental metabolic difference between $C$. gracilis and other Campylobacter species. In our study we found other evidence which indicates that these taxa can be distinguished. Strains belonging to $C$. gracilis did not exhibit malate dehydrogenase activity, in contrast to other campylobacters. Also, the cell wall fatty acid patterns of $C$. gracilis were distinct from those of other Campylobacter species. Consistent with the results of Vandamme et al. (16), we found that $C$. gracilis contained 16:0 dimethylaldehyde (C. curvus contained small amounts of 16:0 dimethylaldehyde) and large amounts of 18:1 cis 9 dimethylaldehyde (other Campylobacter species contained no 18:1 cis 9 dimethylaldehyde). In contrast to Vandamme et al. (16), we did not find a 16-C aldehyde in $C$. gracilis. Finally, a DNA-DNA hybridization analysis revealed that the level of homology between $C$. gracilis DNA and $C$. rectus DNA was low.

The type strain of $C$. gracilis, strain ATCC $33236^{\mathbf{T}}$, was at the edge of the $C$. gracilis cluster defined by the cell wall fatty acid analysis and hybridized less strongly than WAL 8030 to the other $C$. gracilis strains. C. gracilis WAL 8030 (a strain that occurred at the center of the cellular fatty acid cluster) exhibited high levels of DNA homology with other $C$. gracilis strains and a level of DNA homology with C. rectus of $23 \%$. These data suggest that strain ATCC 33236 may not be a good type strain for $C$. gracilis. However, the $C$. gracilis strains that we used were not specifically oral isolates but were (with one exception) obtained from infections that occurred above the diaphragm (in contrast to the Sutterella strains, which were obtained for the most part from gastrointestinally related infections); thus, these strains may represent a different subgroup of $C$. gracilis than the subgroup used when strain ATCC 33236 was chosen as the type strain. Two of the isolates, strains WAL 10160 and WAL 10204 (a periodontal isolate and a pleural fluid isolate, respectively), exhibited higher levels of homology with the type strain $(\sim 75 \%)$ than the other isolates did $(\sim 30$ to $40 \%)$. Our data (particularly our DNA homology data) indicated that the heterogeneity of $C$. gracilis strains merits further study.

The strains that originally were identified as $C$. gracilis but differed in genetic and biochemical characteristics belong to a new genus and a new species, for which we propose the name Sutterella wadsworthensis. The Sutterella strains differed from the $C$. gracilis type strain and other typical $C$. gracilis strains and from other Campylobacter strains in a number of characteristics (Table 4).
Description of Sutterella gen. nov. Sutterella (Sut.ter.el'la. M.L. dim. fem. n. Sutterella, named in memory of Vera Sutter, respected colleague and director of the Wadsworth Anaerobe Laboratory for 20 years). Gram-negative straight rods. Grows in a microaerophilic atmosphere (an atmosphere containing 2 or $6 \%$ oxygen) or under anaerobic conditions. Resistant to $20 \%$ bile disks. Asaccharolytic. Cannot reduce tetrazolium tetrachloride under aerobic conditions if formate and fumarate are added to the medium. Can be differentiated from C. gracilis and Campylobacter species by the characteristics shown in Table 4. 16S rRNA sequence and DNA hybridization data indicate that the genus Sutterella is not related to C. gracilis or other Campylobacter species.

The genus Sutterella contains one species, Sutterella wadsworthensis, which is the type species.

Description of Sutterella wadsworthensis sp. nov. Sutterella wadsworthensis (wads.worth'en.sis. M.L. adj. wadsworthensis, from Wadsworth, referring to the Wadsworth Anaerobe Laboratories, VAMC West Los Angeles, where the strains were identified). Gram-negative straight rods that are 0.5 to $1 \mu \mathrm{m}$ wide and 1 to $3 \mu \mathrm{m}$ long. Urease negative. Oxidase negative. Indoxyl acetate negative. Reduces nitrate. Isolated mainly from infections of gastrointestinal tracts. May be resistant to metronidazole. The type strain is strain WAL 9799 (= ATCC 51579).

\section{ACKNOWLEDGMENT}

This work was supported in part by VA Medical Research Funds.

\section{REFERENCES}

1. Brenner, D. J. 1982. Escherichia vulneris: a new species of Enterobacteriaceae. J. Clin. Microbiol. 15:1133-1140.

2. Etoh, Y., F. E. Dewhirst, B. J. Paster, A. Yamamoto, and N. Goto. 1993. Campylobacter showae sp. nov., isolated from the human oral cavity. Int. J. Syst. Bacteriol. 43:631-639.

3. Felsenstein, J. 1981. Evolutionary trees from DNA sequences: a maximum likelihood approach. J. Mol. Biol. 17:368-376.

4. Frothingham, R., R. L. Allen, and K. H. Wilson. 1991. Rapid 16S ribosomal DNA sequencing from a single colony without DNA extraction or purification. BioFeedback 11:40-44.

5. Han, Y.-H., R. M. Smibert, and N. R. Krieg. 1991. Wolinella recta, Wolinella curva, Bacteroides ureolyticus, and Bacteroides gracilis are microaerophiles, not anaerobes. Int. J. Syst. Bacteriol. 41:218-222.

6. Johnson, C. C., J. F. Reinhardt, M. A. Edelstein, M. E. Mulligan, W. L. George, and S. M. Finegold. 1985. Bacteroides gracilis, an important anaerobic bacterial pathogen. J. Clin. Microbiol. 22:799-802.

7. Laemmli, U. K., and M. Favre. 1973. Maturation of the head of bacteriophage T4. DNA packaging events. J. Mol. Biol. 80:575-599.

8. Molitoris, E., S. M. Finegold, and H. Wexler. 1991. Use of triphenytetrazolium chloride (TTC) to facilitate determination of ceftizoxime (ZOX) MICs against anaerobes, abstr. A25, p. 5. In Abstracts of the 91st General Meeting of the American Society for Microbiology 1991. American Society for Microbiology, Washington, D.C. 
9. Moss, C. W., and O. L. Nunez-Montiel. 1982. Analysis of short-chain acids from bacteria by gas-liquid chromatography with a fused-silica capillary column. J. Clin. Microbiol. 15:308-311.

10. Paster, B. J., and F. E. Dewhirst. 1988. Phylogeny of campylobacters, wolinellas, Bacteroides gracilis, and Bacteroides ureolyticus by $16 \mathrm{~S}$ ribosomal ribonucleic acid sequencing. Int. J. Syst. Bacteriol. 38:56-62.

11. Popovic-Uroic, T., C. M. Patton, M. A. Nicholson, and J. A. Kiehlbauch 1990. Evaluation of the indoxyl acetate hydrolysis test for rapid differentiation of Campylobacter, Helicobacter, and Wolinella species. J. Clin. Microbiol 28:2335-2339.

12. Shah, H., and S. E. Gharbia. 1992. Biochemical and chemical studies on strains designated Prevotella intermedia and proposal of a new pigmented species, Prevotella nigrescens sp. nov. Int. J. Syst. Bacteriol. 42:542-546.

13. Shah, H. N., and M. D. Collins. 1989. Proposal to restrict the genus Bacteroides (Castellani and Chalmers) to Bacteroides fragilis and closely related species. Int. J. Syst. Bacteriol. 39:85-87.

14. Summanen, P., E. J. Baron, D. Citron, C. Strong, H. M. Wexler, and S. M Finegold. 1993. Wadsworth anaerobic bacteriology manual, 5th ed. Star Publishing Co., Belmont, Calif.
15. Tanner, A. C. R., S. Badger, C. H. Lai, M. A. Listgarten, R. A. Visconti, and S. S. Socransky. 1981. Wolinella gen. nov., Wolinella succinogenes (Vibrio succinogenes Wolin et al.) comb. nov., and description of Bacteroides gracilis sp. nov., Wolinella recta sp. nov., Campylobacter concisus sp. nov., and Eikenella corrodens from humans with periodontal disease. Int. J. Syst. Bacteriol. 31:432-445.

16. Vandamme, P., M. I. Daneshvar, F. E. Dewhirst, B. J. Paster, K. Kersters, H. Goossens, and C. W. Moss. 1995. Chemotaxonomic analyses of Bacteroides gracilis and Bacteroides ureolyticus and reclassification of B. gracilis as Campylobacter gracilis comb. nov. Int. J. Syst. Bacteriol. 45:145-152.

17. Whiley, R. A., and D. Beighton. 1991. Emended descriptions and recognition of Streptococcus constellatus, Streptococcus intermedius, and Streptococcus anginosus as distinct species. Int. J. Syst. Bacteriol. 41:1-5.

18. Wilson, K. H., R. Blitchington, B. Hindenach, and R. C. Greene. 1988. Species-specific oligonucleotide probes for rRNA of Clostridium difficile and related species. J. Clin. Microbiol, 26:2484-2488.

19. Zintz, C. B., and D. C. Beebe. 1991. Rapid reamplification of PCR products purified in low melting point agarose gels. BioTechniques 11:158-162. 